\title{
Edoxaban Tosylate
}

National Cancer Institute

\section{Source}

National Cancer Institute. Edoxaban Tosylate. NCI Thesaurus. Code C96542.

The tosylate salt form of edoxaban, an orally active inhibitor of coagulation factor Xa (activated factor $\mathrm{X}$ ) with anticoagulant activity. Edoxaban is administered as edoxaban tosylate. This agent has an elimination half-life of 9-11 hours and undergoes renal excretion. 